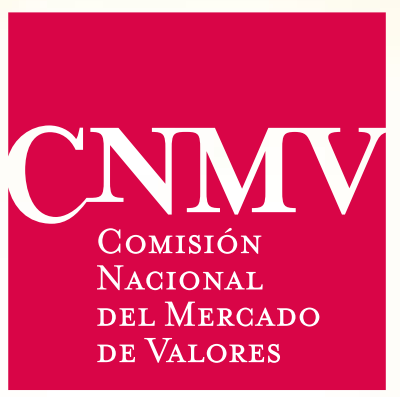

Could regulation of the ABS secondary market improve social welfare?

Ramiro Losada López 





\section{Could regulation of the ABS secondary market improve social welfare?}

Ramiro Losada López 
Ramiro Losada López pertenece al Departamento de Estudios, Estadísticas y Publicaciones de la Comisión Nacional del Mercado de Valores.

Las opiniones expresadas en este documento reflejan exclusivamente el criterio del autor y no deben ser atribuidas a la Comisión Nacional del Mercado de Valores.

La Comisión Nacional del Mercado de Valores, al publicar esta serie, pretende facilitar la difusión de estudios que contribuyen al mejor conocimiento de los mercados de valores y su regulación.

La Comisión Nacional del Mercado de Valores difunde la mayoría de sus publicaciones a través de la red Internet en la dirección www.cnmv.es

(C) CNMV. Se autoriza la reproducción de los contenidos de esta publicación siempre que se mencione su procedencia.

ISBN: $978-84-87870-93-4$

Depósito Legal: BI-3081-09

Maquetación e impresión: Composiciones Rali, S.A. 


\section{Abstract}

This paper examines a model of market making in the ABS market with heterogeneous investors and a lack of price transparency. In this set-up, market makers enjoy market power due to the diversity of assets that back ABS bonds with the same rating: mortgages, credit cards, loans, corporate bonds, etc. It is shown that in a world with no price transparency, allowing free entry of market makers might not be social optimum. Social welfare would be improved by a regulation to restrict the number of market makers in the ABS market to the extent that price competition is guaranteed providing they are forced to buy and sell all possible types of ABS bonds: RMBS, CMBS, CDO, CLO, etc.

Keywords: ABS market, financial regulation, horizontal differentiation.

JEL Classification: G15, G18, L81. 



\section{Table of contents}

$2 \quad$ The model $\quad 11$

$2.1 \quad$ Modelling investors and market for ABS bonds 11

\begin{tabular}{lll}
\hline 2.2 & The search cost function & 13
\end{tabular}

\begin{tabular}{lll}
\hline 2.3 & Indifferent investors & 14
\end{tabular}

3 Competition among market makers 17

\begin{tabular}{lll}
\hline $3.1 \quad$ Price competition & 17
\end{tabular}

\begin{tabular}{llr}
\hline 3.1 & Price competition & 17
\end{tabular}

3.2 Proportion of investors buying in the ABS market 18

\begin{tabular}{lll}
\hline 3.3 & Equilibrium price in the ABS market for sellers & 19
\end{tabular}

3.4 Number of market makers in the ABS market 20

3.4 Number of market makers in the ABS market 20

\begin{tabular}{llr}
\hline 3.5 & Comparative statics & 21
\end{tabular}

4 Social welfare $r 2$

$5 \quad$ Conclusions and regulatory advice $\quad 25$

$\begin{array}{lr}\text { References } & 27\end{array}$

$\begin{array}{llr}\text { A Appendix } & 29\end{array}$

\begin{tabular}{llr}
\hline A.1 Proof Lemma 1 & 29
\end{tabular}

\begin{tabular}{llr}
\hline A.2 Proof Lemma 2 & 30
\end{tabular}

$\begin{array}{llr}\text { A.3 Proof Proposition } 1 & 32\end{array}$

\begin{tabular}{llr}
\hline A.4 Proof Proposition 2 & 33
\end{tabular}

\begin{tabular}{lll}
\hline A.5 Proof Proposition 3 & 34
\end{tabular} 



\section{Introduction}

Much attention has been devoted to price formation on stock exchanges which are organized as dealer markets. The two main strands of the literature focus on the additional fundamental risk borne by risk averse market makers who are forced to deviate from their optimal portfolio position (for a survey see Stoll (1985), or on the adverse selection risk created by the presence of better-informed "insiders" (Glosten and Milgrom [1985], Kyle [1985]).

Yet, very little work has been done on modelling the strategic interaction of all the participants of such markets. In particular, the adverse selection literature simply imposes a zero-profit condition without explicitly modelling the interaction between competing market makers. While the bidding procedure of Glosten and Milgrom and Kyle might be justifiable in a specialist market in which the specialist observes the total market demand before setting prices, the justification of such a zero-profit condition in typical dealer markets is less obvious. In these markets, competing market makers quote prices and quantities and are obliged by an explicit (London Stock Exchange, New York NASDAQ) or an implicit (Foreign Exchange Markets) convention to stick to their quotations, which are not conditioned upon the flow received by their competitors.

This paper focuses on microstructure, competition and price formation in the dealer market for Asset Backed Securities (hereinafter ABS). The ABS market has special characteristics that differentiate it from the stock exchange or public debt market:

1. Issuers of ABS bonds decide the credit risk of each of the tranches of the issue. In most issues, issuers decide to deliver as many AAA bonds into the market as possible. Although many bonds share the credit risk, they are different from each other. The backed assets differ from one issue to another: mortgages, credit cards, loans, bonds, etc. This means that the evolution of credit, market or liquidity risk of bonds with the same rating may be different.

2. In the secondary ABS market, bonds are traded through market makers. Moreover, many bonds are only traded through one sole market maker ${ }^{1}$.

3. The ABS market lacks pre- and post- price transparency ${ }^{2}$. In dealership markets, market makers are not immediately aware of the trades of the other dealers 3 . This means that investors have to waste utility in searching for the appropriate ABS bond.

\footnotetext{
This fact can be easily checked out in information platforms like Bloomberg or Thomson Reuters.

2 This fact can be easily checked out in information platforms like Bloomberg or Thomson Reuters.

3 For a more complete discussion on the difference between a fragmented dealer market and a centralized market, see Biais (1993).
} 
4. In this market, bond buyers and sellers are qualified investors. The percentage of minority investors is negligible. It could be assumed that market participants are privy to the same amount of information when trading.

5. The principal reasons behind a bondholder's decision to sell are liquidity and asset allocations. Most of the investors buy ABS bonds with the intention of holding them to maturity. They do not usually buy ABS bonds to trade them in the short run.

The aim of this paper is to provide an explicit game-theoretic treatment of the effects of competition in the ABS dealer market. In particular, what will be investigated is the impact of the intensity of competition among market makers on the welfare of investors. Moreover, it will investigate whether social welfare could be improved by regulation.

It turns out that market makers sell ABS bonds with different characteristics (they are backed by different assets) but that have the same credit quality, usually AAA to investors. These different bond characteristics mean that market makers do not sell homogeneous bonds to final investors. This, and the fact that one sole market maker often trades a bond, may mean that the ABS bonds market is not perfectly competitive.

Therefore, market power of market makers relative to investors may play a significant role in price formation. Market power may be an important unexamined component of the bid/ask spread. Thus, dealers may have the market power to set the spread wider than the zero-expected profit-per-trade prices ${ }^{4}$. They could also profit from their market power by not offering some of the ABS bonds in the secondary market.

If market makers enjoyed market power, given the ABS market framework, it might not be socially optimal to promote free entry in the ABS market. It could be welfare improving to restrict entry by regulation. In industries where firms offer different products but with the same quality, it is often better from a social point of view to restrict entry by regulation 5 .

This is the first paper that considers monopolistic competition in a market making model. It could be considered as complementary to Spulber (1996). In that paper, a model of market making with heterogeneous intermediaries, bond buyers and market makers is presented. Market makers sell a homogeneous asset but investors and bond sellers must engage in a time-consuming search for the best price.

The remainder of the paper is organized as follows. Section 2 presents the model and describes investors, bond buyers and market makers. Section 3 analyzes the outcome of competition among market makers. Section 4 analyzes the social welfare benchmark for the ABS market and compares it with the outcome of competition. Finally, section 5 lays out the conclusions and regulatory advice.

4 The literature about microstructure assumes that financial markets are perfectly competitive. This idea may not fit very well in a financial market where there is no price transparency and which is not centralized in an exchange. However, there are a few papers that deal with the issue of market makers market power but in different frameworks, for example Dennert (1993) and Rhodes-Kropf (2005).

5 It is well known that entry into industries like the taxi industry or the retail distribution industry are restricted by regulation. 


\section{The model}

\subsection{Modelling investors and market for ABS bonds}

This model is an extension of the model by Salop (1979). In this variant, the economy that is envisioned consists of two types of securities. The one upon the analysis is focused on which are the ABS bonds with the same rating and an outside asset with the same rating which represents other bond markets. It is considered that in the market for ABS there are market makers that buy bonds from bond sellers and sell bonds to bond buyers (investors). Bond sellers and investors do not trade directly with each other. Market makers have decreasing average costs and are involved in a monopolistic competition where bonds are differentiated. Investors have the option of investing in ABS bonds or in the other alternative securities according to their preferences, prices, and the distribution of ABS bonds in the product space. The population of investors is normalized to one. The identity of market makers is commonly known. Market makers quote prices privately to investors upon request.

Each investor has a most preferred ABS bond $b^{*}$. A bond $b$ different from the most preferred specification is valued lower according to preferences in product space $U\left(b, b^{*}\right)$. The product space of the ABS market is taken to be a unit-circumference of a circle. Investors are located uniformly along the circumference. These assumptions allow a market equilibrium with identical prices for equally-spaced bonds. Eliminating technical difficulties makes it simpler to analyze the qualitative equilibrium properties of the model. The model reflects the fact that although ABS bonds are created with the same credit risk -they are usually rated AAA- they can evolve in different ways in the long run. ABS bonds are found in the market backed by a group of mortgages (MBS bons), or by a group of corporate bonds (CDO bonds), or by a group of CDO bonds (CDO squared bonds), etc ${ }^{6}$. Thus, given the same initial credit risk, there are investors who prefer to invest in an ABS bond backed by mortgages than in an ABS bond backed by corporate bonds while other investors prefer the opposite.

It is also assumed that investors have to incur search costs in order to be aware of the ABS bonds' locations and prices. Investors take a two-step decision. First, they decide if they want to search for ABS bonds by getting in touch with market makers. In the event that an investor decides not to search, he obtains zero utility.

The ABS bond searching process is as follows: in the first stage the investor decides whether to ask two market makers or to buy a bond from an alternative bond market.

6 In the book by Fabozzi, F. and Choudhry, M. (2004), The Handbook of European Structured Financial Products, Willey Finance, there is a detailed description of different ABS bonds backed by different pools of assets. 
If the market makers own the two closest bonds to investor preference, the investor stops searching. If the market makers do not own either of the two closest bonds, the investor decides whether to ask a new market maker about his bonds or to stop searching and buy a bond from an alternative market. If, with the new market maker's bonds information, the investor acquires information about the two closest bonds to his preference, the investor stops searching. If the investor does not acquire that information, he decides again whether to ask a new market maker. The search process goes ahead until the investor attains the desired information about the two closest bonds to his preference or until the investor decides to give up searching. In the latter case the utility the investor gets is $-\beta(n)$, where $n$ is the number of market makers which operate in the ABS market in which the investor has requested bond information.

If there are $L$ differentiated bonds at prices $p_{i}$ and locations $b_{i}$, an investor that decides to make an ABS bond search and whose most preferred specification is $b^{*}$ will obtain a utility

$$
v-\beta(n)-t\left|b_{i}-b^{*}\right|-p_{i}
$$

with the probability that he obtains the information about the two closest bonds to his preferences, $\operatorname{Pr}(n)$. If the investor does not acquire the desired information about the ABS bond after asking $n$ market makers, he will obtain a utility:

$$
-\beta(n)
$$

with probability $1-\operatorname{Pr}(n)$. The probability $\operatorname{Pr}(n)$ increases the higher the number of market makers asked.

By assumption, $\beta(n), n=1, \ldots \ldots \ldots . ., N$ is always bounded in the interval $\left[v-k-q-\frac{3 t}{2 \mathrm{~L}}, v\right.$ $-k-q$ ], where $q$ is the price at which market makers buy ABS bonds and $k$ represents the other marginal costs a market maker incurs when he trades in the ABS market7. Parameter $t$ reflects how different investors perceive the available ABS bonds.

Each market maker sells at least one of the L ABS bonds available in the market. For the sake of simplicity, it is assumed that each market sells the same number of different types of ABS bonds, $L / N$, where $N$ is the total number of market makers which operate in the ABS bond market ${ }^{8}$. The $L$ bonds are sold by two or more market makers ${ }^{9}$. Also for simplicity's sake, it is assumed that market makers do not sell bonds that are consecutively located in the circumference. If a market maker sells ABS bonds that are consecutively located in the investors' preference circle, he is willing to charge higher prices to investors because in some types of ABS bonds he

7 The variable $k$ could be interpreted as the opportunity costs market makers have from the time that they buy a bond until they sell it.

8 As the reader could easily deduce, in many of the cases they could consider $L / N$ is not an integer. In those cases it could be interpreted that the demand by each investor of one of the ABS bonds is satisfied by the $N$ market makers with equal probabilities.

9 Spulber (1993) shows a set up where many different market makers try to sell the same asset. In the ABS market it is very common that only one market maker sells a bond. To a certain extent, this article can be considered as complementary to Spulber's (1993). 
only competes with himself. An example of a set up that includes such an assumption is analyzed in appendix B. Although that set up could be more realistic, it would add complexity to the model and would not change the qualitative results.

The ABS market is modelled as the result of a game consisting of the following stages:

1. $\quad N$ market makers decide to enter into the ABS market to buy and sell bonds.

2. Original holders of bonds sell the bonds to market makers. The bond sellers behave as price takers.

3. When market makers hold the bonds, they compete by price. Investors decide whether to enter into a search process to buy a unit of their most preferred ABS bond given the prices set by market makers or to buy a bond from an alternative bond market.

It is important to point out that investors decide to enter into a search process knowing no ABS bonds price due to a lack of transparency in the market. Moreover, it is assumed that when an investor asks a market maker for the price of an ABS type of bond, the market maker cannot infer the location of investor's preference in the circumference. Under that assumption, market makers price discrimination is avoided when they sell more than one type of ABS bond ${ }^{10}$.

\subsection{The search cost function}

Investors are involved in a sequential search process. Each investor starts the process by asking two market makers about the prices and characteristics of the bonds they sell. All market makers have the same probability of being asked. If the investor acquires the information about the two closest ABS bonds to his preference he stops searching and decides whether to buy his most preferred ABS or the alternative bond which gives him zero utility. If the investor does not acquire the desired information about the ABS bonds, he decides whether to ask a new market maker about their bond characteristics and prices or to stop searching. If he decides to stop searching, he buys the alternative bond. Any time an investor decides to ask a new market maker, he incurs a cost of $c \leq u$. At any stage, if the investor decides to keep on searching he chooses a market maker from among the remaining unasked market makers with equal probability. The process goes on until the investor gets the desired information about the ABS bonds or until he gives up searching for his most preferred bonds and their prices.

It is straight forward that as the investor asks more market makers, the probability of acquiring the information about their most preferred ABS bonds increases. So, when the investor asks $n$ market makers that probability is:

10 A rational strategy that any investor could follow so as not to let a market maker guess his position in the circumference is to ask the price of several of the ABS bonds that a market maker or several market makers offer. 


$$
\operatorname{Pr}(n)=\frac{n(n-1)}{N(N-1)}, n=1, \ldots ., N
$$

In order to work out the maximum number, $n^{*}$, of market makers that investor asks, a decision tree is solved by backward induction.

Lemma 1 Investors ask a maximum number of market makers $n^{*}=N$.

Proof: See Appendix

Investors never give up searching among market makers until they obtain the information about the closest ABS bonds to their preferences. Therefore, when an investor decides to enter into bond searching, the investor always buys one unit of any of the available ABS bonds ${ }^{11}$.

Given the lemma 1, the cost search function is:

$$
\beta(N)=\sum_{i=2}^{N} \prod_{j=2}^{i}(1-\operatorname{Pr}(j-1)) \operatorname{Pr}(j) j c
$$

This function $\beta(N)$ is increasing and convex with respect to $N$.

\subsection{Indifferent Investors}

In this set-up, there are $2 L$ indifferent investors. There are two different indifferent investors for each available bond in the ABS market since there are investors who finally choose not to buy any of the ABS bonds. So, the indifferent investors hold the following conditions:

$1 \quad$ There must be investors who are willing to buy any of the available ABS bonds. This means that:

$$
v-\beta(N)-t\left|b_{i}-b^{*}\right|-p_{i} \geq 0
$$

At this stage, it is assumed that $\delta$ investors is the proportion of investors that do not buy any of the $L$ ABS available bonds ${ }^{12}$. The reader should notice that the total demand for ABS is $1-\delta$.

2 Among the investors that are willing to buy ABS bonds, the indifferent ones are located at a distance of $b_{i}, i=1, \ldots \ldots ., 2 L$ from the location of each of the $L$, where $b_{i}$ is determined by:

11 Given lemma 1, it is easy to prove that an investor that decides to search in the ABS market also decides to buy on an ABS market

12 Since the model is symmetric, it is assumed from the beginning that the proportion of investors that do not buy any of the $L$ bonds is the same. 


$$
p_{i}+t b_{i}=p_{j}+t\left(\left(\frac{1}{L}-\delta\right)-b_{i}\right)
$$

or equivalently:

$$
b_{i}=\frac{1}{2}\left(\frac{1}{L}-\delta+\frac{\left(p_{j}-p_{i}\right)}{t}\right)
$$

In determining the indifferent consumers, the assumption that market makers do not guess the location of investors in the circumference when they ask for ABS bond prices is particularly important. If market makers became aware of the location of investor preferences, they would be willing to discriminate among investors by offering them different prices for the same ABS bond.

Figuring out the indifferent consumers makes it possible to work out the demand for each of the ABS bonds. So, the demand for each of the ABS bonds is twice the position in the circumference of the indifferent investor:

$$
D_{i}\left(p_{j}, p_{i}\right)=\frac{1}{L}-\delta+\frac{\left(p_{j}-p_{i}\right)}{t}, i=1, \ldots, L
$$

and where $j \neq i$ are the nearest bonds to bond $i$. 



\section{Competition among market makers}

\subsection{Price competition}

In this section the game presented in the previous section is solved and analyzed. To solve the game, the backward induction procedure is used to look for the Subgame Perfect Nash Equilibrium. So, at the price competition stage, $\delta$ is fixed as well as $q$ and $N$. By assumption, market makers do not hold ABS bonds to sell that are consecutively located in the circumference. Hence, market makers solve the following maximization problems for each of the bonds ${ }^{13}$ :

$$
\max _{p_{i}} \Pi_{i}=\left(p_{i}-k-q\right)\left(\frac{1}{L}-\delta+\frac{\left(p_{j}-p_{i}\right)}{t}\right)-f, i=1, . ., L \text { and } j \neq i
$$

where $j$ is the nearest bond in the circumference to $i$ and $f$ is the fixed cost a market maker pays to be able to trade in the ABS market.

Taking the first order condition with respect to $p_{i}$, it is obtained:

$$
\frac{\partial \Pi_{i}}{\partial p_{i}}=\frac{1}{L}-\delta-\frac{1}{t}\left(2 p_{i}-p_{j}-k-q\right)=0
$$

From the system of equation above and by symmetry among the $L$ ABS bonds, equilibrium prices are $^{14}$ :

$$
p_{1}^{*}=p_{2}^{*}=\ldots . .=p_{L}^{*}=p^{*}=k+q+t\left(\frac{1}{L}-\delta\right)
$$

The equilibrium prices are above the cost market makers have paid so market makers enjoy market power. The market makers mark-up:

$$
p^{*}-k-q=t\left(\frac{1}{L}-\delta\right)
$$

13 In the case where $L / N$ is not an integer, there is a bond that is not exclusively owned by a market maker. It is assumed that the price of that bond is set by a market maker who does not have either of the two closet bonds to it.

14 The second order condition of the profit functions of each of the bonds trivially satisfies the condition to be concave. In the Appendix, in the proof of lemma 2 it is proved that the profit functions are concave with respect to $p_{i}$. 
depends on the degree of substitution among consecutive bonds, $\frac{1}{t}$. The lower the degree of substitution, the higher the prices market makers can charge to the proportion of final investors that have decided to buy in the ABS market.

\subsection{Proportion of investors buying in the ABS market}

Following the backward induction procedure, the next step is to work out the proportion of bond investors that finally buy in the ABS market ${ }^{15}$. In the model, this proportion is represented by the complementary of parameter $\delta$.

Investors buy in the ABS market if the utility they enjoy is higher than zero; zero being the utility they enjoy if they buy in an alternative bond market. In order to determine the demand in the ABS market, it is useful to figure out which investors are indifferent as regards buying in the ABS market and buying in the alternative bond market. Such investors, $x_{i}$, hold the following condition:

$$
v-\beta(N)-t x_{i}-p^{*}=0, i=1, \ldots, L, \text { where } p^{*}=k+q+t\left(\frac{1}{L}-\delta\right) .
$$

Working out the equation it comes out as:

$$
x_{i}=\frac{v-\beta(N)-k-q}{3 t}
$$

The position of the indifferent investors means that the proportion of investors that give up on the ABS market and the demand for any ABS bonds are respectively:

$$
\delta(v, N, k, q, t, L)=\frac{1}{L}-\frac{2(v-\beta(N)-k-q)}{3 t}
$$

and

$$
d^{*}=\frac{1}{L}-\delta(v, N, k, q, t, L)=\frac{2(v-\beta(N)-k-q)}{3 t} .
$$

The condition that $\beta(N) \in\left[v-k-q-\frac{3^{t}}{2 L}, v-k-q\right]$ guarantees that $d^{*} \in\left[0, \frac{1}{L}\right]$. The price that market makers set in the first stage of the game influences the final demand for bonds in two different ways: An increase in the price causes the demand to be lower because investors may change to buy a different ABS bond or may switch to an alternative bond market to buy the bond. The difference of this model with respect to Salop (1979) is that in the latter model a change in the final price would only cause that the investors might choose a different ABS bond.

15 It is important to point out that investors decide to be involved in a search process in the ABS market before they know the ABS prices because it is assumed that in the ABS market there is a lack of price transparency. 


\subsection{Equilibrium price in the ABS market for sellers}

The previous step in the resolution of the game gave the demand for each of the bonds, $d^{*}$. In the model, it is assumed that ABS bond sellers are price takers. This assumption tries to pick up the fact that most sellers of these kinds of bonds take their bonds to the market for liquidity reasons. So, it is assumed that the supply function of bonds is:

$$
s=\frac{q-r}{\gamma}
$$

where $r$ is a reservation value, none of the ABS bond holders will take his bond to the market if the price $q$ is below $r . \gamma$ is the supply function quantity sensitivity to the market price that sellers receive for their bonds.

The equilibrium price is determined through the equilibrium condition $d^{*}=s$ :

$$
q^{*}=\frac{2 \gamma(v-\beta(N)-k)+3 t r}{2 \gamma+3 t}, \text { where } q^{*} \in\left[r, r+\gamma \frac{1}{L}\right]
$$

The price that is paid to bond sellers is determined through a crossover between the market power that market makers enjoy, represented by $t$, and the willingness of the bond sellers to offer their bonds, $\gamma$. It is important to note that to the extent that market makers enjoy more market power in the final market they also enjoy a buying price, $q$, closer to the bond sellers reservation value, $r$. This happens because as $t$ is higher the ABS bonds demand is lower due to competition from other bond markets (specially public debt markets). However, bond sellers enjoy higher prices than $r$ when $v-\beta(N)-k$ is high. As $v-\beta(N)-k$ increases, the demand for ABS bonds is higher in the final market because they face less competition from other bond markets.

The result of price competition among market makers and the determination of the equilibrium price that is paid to bond sellers make it possible to determine the equilibrium ABS bond price for investors and the proportion of investors in the ABS market:

Lemma 2 The market makers charge investors of ABS bonds:

$$
p^{*}=\frac{2(\gamma+t)(v-\beta(N))+(k+r) t}{2 \gamma+3 t}, p^{*} \in\left[k+r, k+r+(\gamma+t) \frac{1}{L}\right]
$$

The proportion of investors that buy each of $L$ ABS bonds is:

$$
d^{*}=\frac{2(v-\beta(N)-k-r)}{2 \gamma+3 t}, d^{*} \in\left[0, \frac{1}{L}\right]
$$

Proof: See Appendix 
The result of lemma 2 means that the equilibrium profit for each of the market makers is:

$$
\begin{gathered}
\Pi_{n}^{*}=\frac{L}{N}\left(p^{*}-k-q^{*}\right) d^{*}-f, \Rightarrow \\
\Rightarrow \Pi_{n}^{*}=\frac{L}{N} t\left(\frac{2(v-\beta(N)-k-r)}{2 \gamma+3 t}\right)^{2}-f, \\
\Rightarrow \Pi_{n}^{*}=\frac{L}{N} t d^{*_{2}}, n=1, \ldots ., N, \\
\Pi_{n}^{*} \in\left[0, t \frac{1}{N L}-f\right] .
\end{gathered}
$$

It is important to remember that these equilibrium prices and proportion of investors buying in the ABS market are based on assumptions that make market makers behave symmetrically. In a more realistic set-up where market makers are not located symmetrically, or where they do not share the same operational cost, equilibrium prices would vary from one market maker to another ${ }^{16}$.

Equilibrium proportions of ABS investors as well as the equilibrium prices in the final market do not depend on the number of bonds sold, $L$. This result differs from Salop (1979) where prices and quantities depend on the number of products sold in the market ${ }^{17}$. Given the competition from the other bond markets, market makers offer as many different bonds to investors as they can from the primary market as it matches better investors preferences better. With this strategy, market makers can face better the competition from other bond markets.

\subsection{Number of market makers in the ABS market}

In the last stage of the resolution of the game, and given the results in the previous stages, the number of market makers that operate in the ABS market can be calculated:

Proposition 1 If $\beta(N)<v-k-r-\frac{3 t+2 \gamma}{2 L}$, the number of market makers is:

$$
N^{*} \text { such that } N \geq 2
$$

such that $N$ is the integrer that satisfies:

$$
\frac{L}{N} t\left(\frac{2(v-\beta(N)-k-r)}{2 \gamma+3 t}\right)^{2}-f=0 .
$$

Proof: See Appendix

16

The assumption that market makers have different operational costs or even different perceptions of the value of a financial asset is justified by following Ho and Stoll (1983) and Biais (1993) and by assuming that risk-averse dealers have different inventories and different expected values of an asset.

17 In Salop (1979), the symmetric equilibrium price and quantity are $p^{*}=c+\frac{t}{L}$ and $d^{*}=\frac{1}{L}$, where $c$ is the marginal cost of the product sold. 
Market makers are considered to compete in a market with free entry. Therefore, market makers will enter the ABS market up to the number that makes the profit of each market maker to be zero or close to zero. If a new market maker entered the ABS market when there are already $N^{*}$ market makers, all market makers would make negative profits.

\subsection{Comparative statics}

In the preceding subsection, the equilibrium buying and selling prices and the equilibrium proportion of investors that buy bonds in the ABS market were presented. It may be interesting to show how these equilibrium variables behave to changes in the independent variables of the model $(L, v, k, r, t, y)$.

So, it is clear that $p^{*}, q^{*}$ and $d^{*}$ have positive derivatives with respect to $v \cdot p^{*}$ is also increasing with respect to $k$ and $r$. However, $q^{*}$ is decreasing with respect to $k$ and increasing with respect to $r, d^{*}$ is decreasing in both variables. When $v$ gets higher the price charged to investors and the buying price, as well as the proportion of investors that buy ABS bonds, are also higher. This happens because more investors find it more attractive to buy ABS bonds rather than buy in other bond markets. As the proportion of buyers is higher, market makers can charge higher prices without losing investors. The buying price increases as a consequence of $d^{*}$ behaviour.

The relationship between $d^{*}$ and the variables $t$ and $\gamma$ is also clear. $d^{*}$ has negative derivatives with respect to $t$ and $\gamma$. However, the relationship between $p^{*}$ and the variables $t$ and $\gamma$ is not so clear at first sight. If the derivatives of $p^{*}$ and $q^{*}$ with respect to $t$ and $\gamma$ are taken, it can be proved that:

$$
\begin{aligned}
& \frac{\partial p^{*}}{\partial t}<0, \frac{\partial q^{*}}{\partial t}<0, \\
& \frac{\partial p^{*}}{\partial \gamma}>0 \frac{\partial q^{*}}{\partial \gamma}>0 .
\end{aligned}
$$

It is found that $p^{*}$ is decreasing with $t$. This happens because as $t$ gets higher, fewer investors are attracted to buying in the ABS market. Market makers must lower the price to face higher competition from the other bond markets. This fact also has important consequences in the behaviour of $d^{*}$ and $q^{*}$ with respect to $t$. Although market makers charge lower prices to investors as $t$ gets higher, investors prefer to switch to other alternative bond markets. A lesser proportion of investors, $d^{*}$, buy a bond in the ABS market. A lower proportion of investors in the final market results in a lower demand of market makers when they meet bond sellers in the competitive market. The immediate consequences of lower demand is that bond sellers receive a lower price, $q^{*}$.

It is also found that $p^{*}$ increases with respect to $\gamma$. This happens because as $\gamma$ increases, ceteris paribus, sellers of bonds in the competitive market receive a higher price $q^{*}$. Market makers end up reflecting the increase in the price paid to bond sellers due to an increase in $\gamma$ by raising their final price to investors. As $p^{*}$ increases with $\gamma$, final 
investors find it less attractive to buy ABS bonds, which means that the proportion of investors, $d^{*}$ decreases with $\gamma$.

From the behaviour of $d^{*}$, the behaviour of market makers' profits with respect to the independent variables of the model can be inferred, as $\Pi_{n}^{*}=(L / N) t\left(d^{*}\right)^{2}-f$. Nevertheless, the reasons that backed that behaviour for the variables $t$ and $\gamma$ are not evident. For these variables, the derivatives are:

$$
\frac{\partial \Pi_{n}^{*}}{\partial t}<0, \frac{\partial \Pi_{n}^{*}}{\partial \gamma}<0
$$

On the one hand, the price markup, $p^{*}-q^{*}-k$, that market makers set increases with respect to $t$. On the other hand, the proportion of investors that decide to buy ABS bonds is decreasing with respect to $t$. However, the second derivative of the markup with respect to $t$ is always lower than the second derivative of $d^{*}$ with respect to $t$.

Finally, it is important to remember that the variables $p^{*}, q^{*}$ and $d^{*}$ may be bounded ${ }^{18}$. The analysis presented above is valid while the variables do not reach the relevant boundary of the intervals ${ }^{19}$. In the event that equilibrium prices and the proportion of investor that buy bonds in the ABS market reach their boundaries, the comparative statics shown so far can change ${ }^{20}$.

At the end of the appendix, the reader can find graphs with examples that show the relationships between the $p^{*}, q^{*}, p^{*}-q^{*}-k$ and $\Pi_{n}^{*}$ with respect to $t$ and $\gamma$ shown above $^{21}$. In those graphs, it can be observed that for a small amount of $t$, the equilibrium variables behave in a different manner. This is caused by the fact that equilibrium variables are at their upper boundaries.

This happens when $N=2$. From $N=3$ on this cannot happen by the assumption that $\beta(N)$ is strictly increasing in $N$.

19 For example, $p^{*}$ increases as $v$ is higher. However, once $p^{*}$ has reached the value $k+r+(\gamma+t) \frac{1}{L}$, any increase in the variable $v$ does not result in an increase in $p^{*}$.

20 Note that once an equilibrium variable reaches a boundary, the other equilibrium variables, profit included, also reach a boundary.

21 In these graphs, it is assumed that $\beta(3)$ is so high that a third market maker cannot enter into the ABS market. 


\section{Social welfare}

It is assumed that the regulator does not influence bond buying and selling prices. This assumption implies that the regulator takes the buying and selling prices resulting from the competition of the previous section as given. So, the social welfare function is defined as the sum of investors' and bond sellers' surplus:

$$
W(N, L)=2 L\left(\int_{0}^{\frac{1}{2} d^{*}}\left(v-\beta(N)-k-q^{*}-t y\right) d y+\int_{0}^{\frac{1}{2} d^{*}}\left(q^{*}-r-\gamma y\right) d y\right)-N f
$$

where

$$
\begin{gathered}
d^{*}=1-\delta(L, v, N, k, r, t, \gamma)=\frac{1}{L}-\left(\frac{1}{L}-\frac{2(v-\beta(N)-k-r)}{3 t+2 \gamma}\right)= \\
=\frac{2(v-\beta(N)-k-r)}{3 t+2 \gamma} .
\end{gathered}
$$

By working out the social welfare function it is obtained:

$$
W(N, L)=L\left((v-\beta(N)-k-r) d^{*}-\frac{1}{4}(t+\gamma) d^{*_{2}}\right)-N f
$$

Proposition 2 The socially optimal number of market makers is the minimum, $N_{s}^{*}=2$.

Proof: See Appendix.

This result gives rise to the following corollary:

Corollary 1 The competition drives the number of market makers above the social optimum. It may be advisable to restrict the number of market makers which operate in the ABS market by regulation.

The optimal number of market makers is the minimum possible, $N_{s}^{*}=2$. This happens because as the number of market makers decreases, the utility of all possible investors rise. This brings as a consequence that a higher number of investors buy any of the available $L$ bonds in the ABS bond market.

Although restricting entry by regulation is also social optimum in the classical models of horizontal differentiation, the reason is different from the one shown for the ABS 
market $^{22}$. In the classical models of horizontal differentiation, an alternative market does not exist. All consumers buy from the horizontally differentiated firms. Thus, as the consumers are captive, too many firms join the industry.

There is an important assumption behind these results. It is assumed that the level of competition is the same with two market makers as with a higher number. In this model, this means that market makers never sell two different bonds that are consequentially located in the preferences circle. Therefore, the result not only implies that the number of market makers may be reduced, it also implies that the two market makers should be global. They should sell all type of bonds: RMBS, CDO, CMBS and ABS backed by credit cards, etc. Furthermore, within each category, they should sell bonds with similar characteristics.

Besides the socially optimal number of market markers, it is also interesting to search for the socially optimal number of different bonds, as this could be another variable the regulator could influence:

Proposition 3 Given a number of market makers, $N$, the optimal number of different bonds available in the secondary amounts to all issued ABS bonds.

Proof: See appendix.

The welfare function rises with the number of different bonds available that are sold by market makers. As the number of different bonds increases, the number of investors that are closer to their most preferred option also increases. It is less attractive to buy bonds in the alternative bond markets. So, the number of investors buying ABS bonds, and hence the social welfare, increases. The regulator would choose to bring all the different issued ABS bonds to the market.

The social optimum coincides with the result that arose when the competition among market makers was analyzed. This is somewhat surprising. At first sight, it would appear to be optimal for market makers not to offer all the different ABS bonds in order to exploit their market power. However, the competition from the other bond markets offsets this. Market makers prefer to bring all possible different ABS bonds to market because it is more likely that investors end up buying an ABS bond than buying from the other bond markets.

In regard to the comparative statics of the welfare function, qualitatively it is the same as the one from $d^{*}$, the portion of investors that buy bonds in the ABS market. The welfare function is higher when $d^{*}$ is higher. So, the welfare function has a positive derivative with respect to $v$. On the other hand, the welfare function has a negative derivative with respect to $k, r, \gamma, t$.

22 For example in Salop (1979). 


\section{Conclusions and regulatory advice}

In this paper the ABS bond market has been analyzed. A model was proposed where investors have heterogeneous preferences about ABS bonds with the same rating and where there is a lack of price transparency in the market. The model addresses the question regarding the optimality of the ABS market microstructure under a competitive framework.

ABS bonds with the same rating are characterized by having a similar credit risk. However, two ABS bonds can have other different characteristics due to the fact that they are backed by different asset pools. In this paper, it is shown that the variety of ABS bonds gives market power to market makers.

It is also shown that under free entry in the market, the number of market makers is higher than the social ideal. This result holds true as long as the level of competition among market makers remains at the same level as under free entry.

Financial regulators should consider further regulation in the ABS bond market. Regulating the entry of market makers to this market could improve social welfare. However, this decision should not be taken alone. Market makers that are allowed by regulation to enter the market should buy and sell all type of ABS bonds: RMBS, CMBS, CDO, CLO, etc. Forcing market makers to buy and sell all type of ABS bonds would guarantee the same level of competition as there is with free entry.

One important conclusion of the paper is that ABS bond homogenization improves social welfare as well as market makers' profits. The latter is at first sight surprising. In principle, the more the bonds sold by market makers are perceived by investors as more homogeneous, the lower the prices they charge to investors. However, if competition from other bond markets is taken into consideration, it can be observed that as ABS bonds are perceived as more homogeneous, more investors prefer to buy ABS bonds. In equilibrium, the rise in the number of ABS bonds sold more than offsets the lower prices charged.

This result could induce financial regulators to place restrictions on how the pool of assets that back ABS bonds are formed. As the pools are more homogeneous, the degree of substitution among ABS bonds decreases. Homogenization could be achieved through regulations that restrict the asset pool of a type of ABS issues so that their characteristics are very similar. An example of this regulation could be the Spanish FTH (Fondos de Titulización Hipotecaria) ${ }^{23}$. In order to homogenize across

$23 \mathrm{FTH}$ issues can only be backed by pools with certain characteristics. These pools are constituted only by residential mortgages whose loan to value is less than 80 per cent. 
ABS types, it could be advisable to introduce some kind of issuer's guarantee to cover part of the issue.

The model could be extended in different ways that may be interesting for further research. An important issue in this market is discovering how the introduction of more transparency in prices affects social welfare. Other extensions are more related with bringing the model closer to reality. So, it could be appealing to incorporate asymmetry among market makers due to different inventories or different risk aversion. 


\section{References}

Biais, B. (1993). Price formation and equilibrium liquidity in fragmented and centralized markets. Journal of Finance, 48, pp. 157-186.

Calcagno, R. and Lovo, S. (2006). Bid-Ask price competition with asymmetric information between market-makers. Review of Economic Studies, 73, pp. 329-355.

Dennert, J. (1993). Price competition between market makers. Review of Economic Studies, 6o, pp. 735-751.

Fabozzi, F. and Choudhry, M. (2004). The handbook of European Structured Financial Products. Willey Finance.

Glosten, L. and Milgrom, P. (1985). Bid, ask and transaction prices in specialist market with heterogeneously informed traders. Journal of Financial Economics, 14, pp. 71-100.

Hansch, O., Naik N. and Viswanathan S. (1998). Do inventories matter in dealership markets? Evidence from the London Stock Exchange. Journal of Finance, 53, pp. $1623-1656$.

Ho, T.S. and Stoll, H.R. (1983). The dynamics of dealer markets under competition. Journal of Finance, 38, pp. 1053-1074.

Martínez-Giralt, X. and Neven D. (1988). Can price competition dominate market segmentation? Journal of Industrial Economics, 36, pp. 431-442.

Mussa, M. and Rosen, S. (1978). Monopoly and product quality. Journal of Economic Theory, 18, pp. 301-317.

Klemperer, P. (1987). The competitiveness of markets with switching costs. Rand Journal of Economics, vol. 18, 1, pp. 138-150.

Kyle, A. (1985). Continuous auctions and insider trading. Econometrica, 53, pp. $1315^{-1335}$.

Rhodes-Kropf, M. (2005). Price improvement in dealership markets. Journal of Business, 78, pp. 1137-1171.

Salop, S.C. (1979). Monopolistic competition with outside goods. The Bell Journal of Economics, 10, pp. 141-156. 
Sapp, S.G. (2002). Price leadership in the spot foreign exchange market. Journal of Financial and Quantitative Analysis, 37, pp. 425-448.

Several authors (1996). The industrial organization and regulation of the securities industry. University of Chicago Press.

Spulber, D.F. (1993). Market making by price-setting firms. Review of Economics Studies, 63, pp. 559-580.

Stoll, H.R. (1985). Alternative views of market making. In Amihud, Y. et al. (eds.), Market making and the changing structures of the securities industries (Lexington: Lexington Books). 


\section{A Appendix}

\section{A.1 Proof Lemma 1}

To work out the proof, the investor's decision problem is calculated following backward induction. At the end of the tree when $n=N, \operatorname{Pr}(N)=1$. At that stage, the investor is aware of the information about all available ABS bonds as he has asked all market markers. He compares the utility he obtains if he decides to search, $v-N c$, where $v=u-t\left|b_{i}-b^{*}\right|-p_{i}$, and the utility if he decides to give up, $-(N-1) c$. It is straight forward to conclude that an investor decides to search if:

$$
v \geq c
$$

This condition holds by assumption. So, at the end of the decision tree the representative investor decides to search. Following the backward induction procedure and given the decision taken in the last stage of the tree, the investor again compares the utility he obtains if he decides to search and the utility if he decides to give up. He decides to search if:

$$
\operatorname{Pr}(N-1)(v-(N-1) c)+(1-\operatorname{Pr}(N-1))(v-N c) \geq-(N-2) c
$$

where

$$
\operatorname{Pr}(n)=\frac{n(n-1)}{N(N-1)}
$$

$\operatorname{Pr}(n)$ is increasing with respect to $n$. So, $\operatorname{Pr}(N-1)<\operatorname{Pr}(N)$, and as $v \geq c$ by assumption, the investor decides to search at stage $N-1$. In the last two stages the investor decides to search.

A generic $n$ stage is considered. Given that from stage $n+1$ on the investor has always taken the decision to search and given that $\operatorname{Pr}(n)$ is increasing in $n$ the investor decides to search if:

$$
\begin{aligned}
& \operatorname{Pr}(n)(v-n c)+(1-\operatorname{Pr}(n)))((\operatorname{Pr}(n+1)(v-(n+1) c)+ \\
+ & (1-\operatorname{Pr}(n+1))((\operatorname{Pr}(n+2) \ldots \ldots . .(v-N c)))) \geq-(n-1) c
\end{aligned}
$$

which it holds. It also holds at the first stage although the expected utility of the search must be compared to zero, the utility of not searching at all and buying an alternative bond. 


\section{A.2 Proof Lemma 2}

At the first stage, market makers maximize the following profit function for each of the ABS bonds they sell:

$$
\Pi_{i}=\left(p_{i}-k-q\right)\left(\frac{1}{L}-\delta+\frac{\left(p_{j}-p_{i}\right)}{t}\right)-f, i=1, \ldots \ldots, \quad L, j \neq i
$$

and where $j \neq i$ are the nearest ABS bonds to bond $i$.

Differentiating with respect to $p_{i}$, the first order condition becomes:

$$
\frac{\left(p_{j}-p_{i}\right)}{t}+\frac{1}{L}-\delta-\frac{1}{t}\left(p_{i}-k-q\right)=0
$$

By symmetry and working out the first order condition it is obtained that:

$$
p^{*}=k+q+t\left(\frac{1}{L}-\delta\right)
$$

If the second order condition is taken, it is obtained:

$$
-\frac{2}{t}<0
$$

Therefore, $p^{*}$ are the prices that maximize profit functions for each of the ABS bonds.

At the second stage, and given $p^{*}$, the proportion of investors that buy ABS bonds can be determined. First, it is necessary to discover which investors are indifferent between buying a bond in the ABS market or in another alternative market. These indifferent investors, $x_{i} i=1, \ldots, L$, hold the following condition:

$$
\begin{gathered}
v-\beta(N)-t x_{i}-p^{*}=0 \Rightarrow \\
\Rightarrow v-\beta(N)-t x_{i}-\left(k+q+t\left(\frac{1}{L}-\delta\right)\right)=0,
\end{gathered}
$$

where

$$
\delta=\frac{1}{L}-2 x_{i}
$$

Substituting the last expression in the equation that gives the indifferent consumers:

$$
v-\beta(N)-t x_{i}-k-q-2 t x_{i}=0 \Rightarrow
$$




$$
\Rightarrow x_{i}^{*}=\frac{v-\beta(N)-k-q}{3 t} i=1, \ldots ., L
$$

So, substituting $x_{i}$ in $\delta$, it is obtained:

$$
\delta(v, N, k, q, t, L)=\frac{1}{L}-\frac{2(v-\beta(N)-k-q)}{3^{t}},
$$

and the demand for ABS from investors is at this stage:

$$
d^{*}=\frac{2(v-\beta(N)-k-q)}{3 t} .
$$

Given $d^{*}$ and given the supply function of bonds:

$$
s=\frac{q-r}{\gamma}
$$

the equilibrium price that the ABS bond seller receives can be worked out:

$$
q^{*}=\frac{2 \gamma(v-\beta(N)-k)+3 t r}{2 \gamma+3 t} .
$$

Subsisting $q^{*}$ in $p^{*}$ and $d^{*}$, the equilibrium final price and the demand for the ABS bonds are obtained:

$$
\begin{gathered}
p^{*}=\frac{2(\gamma+t)(v-\beta(N))+t(k+r)}{2 \gamma+3 t} \\
d^{*}=\frac{2(v-\beta(N)-k-r)}{2 \gamma+3 t} .
\end{gathered}
$$

As by assumption $\beta(N)$ could be binding its boundary, equilibrium price and demand could also be binding their boundaries:

$$
p^{*} \in\left[k+r, k+r+(\gamma+t) \frac{1}{L}\right] \text { and } d^{*} \in\left[0, \frac{1}{L}\right] .
$$




\section{A.3 Proof Proposition 1}

The profit function of each of the market makers is:

$$
\Pi_{n}=\frac{L}{N}\left(p^{*}-k-q^{*}\right) d^{*}-f, n=1, \ldots ., N
$$

where:

$$
\begin{gathered}
p^{*}=\frac{2(\gamma+t)(v-\beta(N))+t(k+r)}{2 \gamma+3 t}, \\
d^{*}=\frac{2(v-\beta(N)-k-r)}{2 \gamma+3 t},
\end{gathered}
$$

and

$$
q^{*}=\frac{2 \gamma(v-\beta(N)-k)+3 t r}{2 \gamma+3 t} .
$$

Substituting $p^{*}, d^{*}$ and $q^{*}$ in the profit function, it is obtained:

$$
\Pi_{n}=\frac{L}{N} t\left(\frac{2(v-\beta(N)-k-r)}{2 \gamma+3 t}\right)^{2}-f
$$

applying the free entry condition. The number of market makers, $N^{*}$, in the ABS market satisfies the following condition:

$$
\frac{L}{N} t\left(\frac{2(v-\beta(N)-k-r)}{2 \gamma+3 t}\right)^{2}-f=0 .
$$




\section{A.4 Proof Proposition 2}

The social welfare function is:

$$
W(N, L)=L\left((v-\beta(N)-k-r) d^{*}-\frac{1}{4}(t+\gamma) d^{*_{2}}\right)-N f
$$

where

$$
d^{*}=1-\delta(L, v, N, k, r, t, \gamma)=\frac{2(v-\beta(N)-k-r)}{3^{t+2 \gamma}} .
$$

The regulator faces the following maximization problem:

$$
\max _{N} L\left((v-\beta(N)-k-r) d^{*}-\frac{1}{4}(t+\gamma) d^{*_{2}}\right)-N f .
$$

Taking the derivative of $W(N, L)$ with respect to $N$, it is obtained:

$$
\begin{aligned}
& \frac{\partial W(N, L)}{\partial N}=L\left(\left(-\frac{\partial \beta(N)}{\partial N}\right) d^{*}+\frac{\partial d^{*}}{\partial N}(v-\beta(N)-k-r)-\frac{t+\gamma}{2} d^{*} \frac{\partial d^{*}}{\partial N}\right)-f= \\
&=L\left(-\frac{\partial \beta(N)}{\partial N} d^{*}+\frac{\partial d^{*}}{\partial N}\left(v-\beta(N)-k-r-\frac{t+\gamma}{2} d^{*}\right)-f .\right.
\end{aligned}
$$

As

$$
\frac{\partial d^{*}}{\partial N}<0
$$

and

$$
\left(v-\beta(N)-k-r-\frac{t+\gamma}{2} d^{*}\right)>0,
$$

because

$$
d^{*}=\frac{2(v-\beta(N)-k-r)}{3^{t+2 \gamma}}
$$

it can be concluded that:

$$
\frac{\partial W}{\partial N}<0,
$$

which implies:

$$
N_{s}^{*}=2 .
$$




\section{A.5 Proof Proposition 3}

The social welfare function is:

$$
W(N, L)=L\left((v-\beta(N)-k-r) d^{*}-\frac{1}{4}(t+\gamma) d^{*_{2}}\right)-N f
$$

where

$$
d^{*}=1-\delta(L, v, N, k, r, t, \gamma)=\frac{2(\nu-\beta(N)-k-r)}{3 t+2 \gamma} .
$$

The regulator faces the following maximization problem:

$$
\max _{L} L\left((\nu-\beta(N)-k-r) d^{*}-\frac{1}{4}(t+\gamma) d^{*_{2}}\right)-N f .
$$

Taking the derivative of $W(N, L)$ with respect to $L$, it is obtained:

$$
\begin{gathered}
\frac{\partial W(N, L)}{\partial L}=\left(v-\beta(N)-k-b^{*}\right) d^{*}-\frac{1}{4}(t+\gamma)\left(d^{*}\right)^{2}+! \\
+L\left((v-\beta(N)-k-r) \frac{\partial d^{*}}{\partial L}-\frac{1}{2}(t+\gamma) d^{*} \frac{\partial d^{*}}{\partial L}\right),
\end{gathered}
$$

where

$$
\frac{\partial d^{*}}{\partial L}=0
$$

Therefore

$$
\begin{gathered}
\frac{\partial W(N, L)}{\partial L}=(v-\beta(N)-k-r) d^{*}-\frac{1}{4}(t+\gamma)\left(d^{*}\right)^{2}= \\
=\left(v-\beta(N)-k-r-\frac{1}{4}(t+\gamma) d^{*}\right) d^{*}>0,
\end{gathered}
$$

because

$$
d^{*}=\frac{2(v-\beta(N)-k-r)}{3^{t+2 \gamma}} .
$$

This implies the optimal number of different bonds equals all issued ABS bonds. 


\section{B An example of the model where market makers can sell consecutively located bonds}

The example consists of deriving the results when there are five bonds. This example differs in one assumption with the model presented in the main body of the paper ${ }^{24}$. In this example, the assumption that ABS bonds sold by market makers must not be consecutively located is relaxed. When there are five bonds in the market, one of the following scenarios may take place:

1 All bonds are sold by alternative market makers.

2 Two consecutive bonds are sold by a market maker. The other three bonds are sold by alternative market makers.

3 Two consecutive bonds are sold by a market maker. Two other consecutive bonds are sold by another market maker. The remaining bond is sold by a third market maker.

4 Three consecutive bonds are sold by a market maker. The other two are sold by alternative market makers.

5 Three consecutive bonds are sold by a market maker. The other two are sold by another market maker.

6 Four consecutive bonds are sold by a market maker. The remaining bond is sold by another market maker.

Within each case, the number of market makers operating may differ. For example in the first case the market described can be achieved when there are five market makers or when there are three. In the latter case, one market maker sells bonds one and three, while another market maker sells bonds two and four and the third sells bond five. Given the six cases described above, the prices at which bonds are sold and bought, quantities exchanged and gross profit earned by market makers for each bond have been worked out. In all tables, some primitives of the model were fixed: $v=102, \beta=1, k=0.5, r=100, \gamma=1$ and $L=5$. 
Case 1:

\begin{tabular}{lrrrrr}
\hline & bond 1 & bond 2 & bond 3 & bond 4 & bond 5 \\
\hline $\mathbf{p}$ & 100.8750 & 100.8750 & 100.8750 & 100.8750 & 100.8750 \\
\hline $\mathbf{q}$ & 100.1250 & 100.1250 & 100.1250 & 100.1250 & 100.1250 \\
\hline $\mathbf{d}$ & 0.1250 & 0.1250 & 0.1250 & 0.1250 & 0.1250 \\
\hline $\mathbf{p - k - q}$ & 0.2500 & 0.2500 & 0.2500 & 0.2500 & 0.2500 \\
\hline profit per bond & 0.03125 & 0.03125 & 0.03125 & 0.03125 & 0.03125 \\
\hline
\end{tabular}

\section{Case 2:}

\begin{tabular}{lrrrrr}
\hline & bond 1 & bond 2 & bond 3 & bond 4 & bond 5 \\
\hline $\mathbf{p}$ & 100.9099 & 100.9099 & 100.8792 & 100.8760 & 100.8792 \\
\hline $\mathbf{q}$ & 100.0901 & 100.0901 & 100.1208 & 100.1240 & 100.1208 \\
\hline $\mathbf{d}$ & 0.0901 & 0.0901 & 0.1208 & 0.1240 & 0.1240 \\
\hline p-k-q & 0.3198 & 0.3198 & 0.2583 & 0.2521 & 0.2583 \\
\hline profit per bond & 0.02881 & 0.02881 & 0.03122 & 0.03125 & 0.03122 \\
\hline
\end{tabular}

\section{Case 3:}

\begin{tabular}{lrrrrr}
\hline & bond 1 & bond 2 & bond 3 & bond 4 & bond 5 \\
\hline $\mathbf{p}$ & 100.9118 & 100.9154 & 100.9142 & 100.9074 & 100.8831 \\
\hline $\mathbf{q}$ & 100.0882 & 100.0846 & 100.0858 & 100.0926 & 100.1169 \\
\hline $\mathbf{d}$ & 0.0882 & 0.0846 & 0.0858 & 0.0926 & 0.1169 \\
\hline $\mathbf{p - k - q}$ & 0.3237 & 0.3309 & 0.3283 & 0.3149 & 0.2662 \\
\hline profit per bond & 0.02853 & 0.02798 & 0.02818 & 0.02915 & 0.03112 \\
\hline
\end{tabular}

\section{Case 4:}

\begin{tabular}{lccccr}
\hline & bond 1 & bond 2 & bond 3 & bond 4 & bond 5 \\
\hline $\mathbf{p}$ & 100.9211 & 100.9571 & 100.9211 & 100.8810 & 100.8810 \\
\hline $\mathbf{q}$ & 100.0789 & 100.0429 & 100.0789 & 100.1190 & 100.1190 \\
\hline $\mathbf{d}$ & 0.0789 & 0.0429 & 0.0789 & 0.1190 & 0.1190 \\
\hline p-k-q & 0.3421 & 0.4143 & 0.3421 & 0.2619 & 0.2619 \\
\hline profit per bond & 0.0270 & 0.0178 & 0.0270 & 0.0312 & 0.0312 \\
\hline
\end{tabular}


Case 5:

\begin{tabular}{lrrrrr}
\hline & bond 1 & bond 2 & bond 3 & bond 4 & bond 5 \\
\hline $\mathbf{p}$ & 100.9271 & 100.9607 & 100.9271 & 100.9184 & 100.9184 \\
\hline $\mathbf{q}$ & 100.0729 & 100.0393 & 100.0729 & 100.0816 & 100.0816 \\
\hline $\mathbf{d}$ & 0.0729 & 0.0393 & 0.0729 & 0.0816 & 0.0816 \\
\hline $\mathbf{p - k - q}$ & 0.3542 & 0.4213 & 0.3542 & 0.3367 & 0.3367 \\
\hline profit per bond & 0.0258 & 0.0166 & 0.0258 & 0.0275 & 0.0275 \\
\hline
\end{tabular}

\section{Case 6:}

\begin{tabular}{lrrrrr}
\hline & bond 1 & bond 2 & bond 3 & bond 4 & bond 5 \\
\hline $\mathbf{p}$ & 100.9250 & 100.9722 & 100.9722 & 100.9250 & 100.8834 \\
\hline $\mathbf{q}$ & 100.0750 & 100.0278 & 100.0278 & 100.0750 & 100.1136 \\
\hline $\mathbf{d}$ & 0.0750 & 0.0278 & 0.0278 & 0.0750 & 0.1136 \\
\hline $\mathbf{p - k - q}$ & 0.3500 & 0.4444 & 0.4444 & 0.3500 & 0.2727 \\
\hline profit per bond & 0.0262 & 0.0123 & 0.0123 & 0.0262 & 0.0310 \\
\hline
\end{tabular}

The relaxation of the assumption that market makers could not sell two or more consecutively located bonds in the investor's preference circle results in new conclusions. When consecutively located bonds are sold by the same market makers, their prices rise. Moreover, the prices of other bonds also rise. This price rise effect is less important the further a bond is located from the bonds sold by the same market maker.

These higher prices also affect other key variables. As a consequence of the competition from alternative bond markets, the outside option of the model, the proportion of investors buying ABS bonds lowers. This lower demand for ABS bonds means that the prices the market maker pays to bond sellers are also lower. So, the mark-ups the market enjoys are higher the more consecutively located bonds are sold by the same market maker. However, these higher mark-ups do not translate into higher profits as the reduction in the proportion of investors buying ABS bonds more than offsets the gains from higher mark-ups.

Nevertheless, one of the main conclusions of the paper still holds true in this example: that market makers must not be specialized. When market makers sell ABS bonds that are very close in their characteristics, they are allowed to charge investors very high prices. The consequence of these prices is a lack of liquidity of the ABS secondary market. So, it is important for social welfare that market makers sell bonds with different characteristics. This conclusion is consistent with market makers not being able to sell bonds consecutively located in the preference circle. 
The other important conclusion in the model where market makers could not sell consecutively located bonds was that the number of market makers should be the minimum which guarantees competition, in that case, two market makers. That conclusion also holds true in this model where the number of ABS bonds in the market is even. Where the number of ABS bonds is odd, it could be socially improving to have three market makers in the market. This could take place since, despite another market maker means paying new fixed costs, a new market maker improves price competition and raises consumer welfare. However, in the real ABS secondary market the number of bonds is large and it is likely that the competition gains derived from a third market maker do not offset its fixed costs.

Market makers' equilibrium profit path under different values of $t$

(whereby $v=100.5, B(2)=1, k=0.2, r=99, \gamma=1, L=8, N=2$ and

$f=0.0255)$.

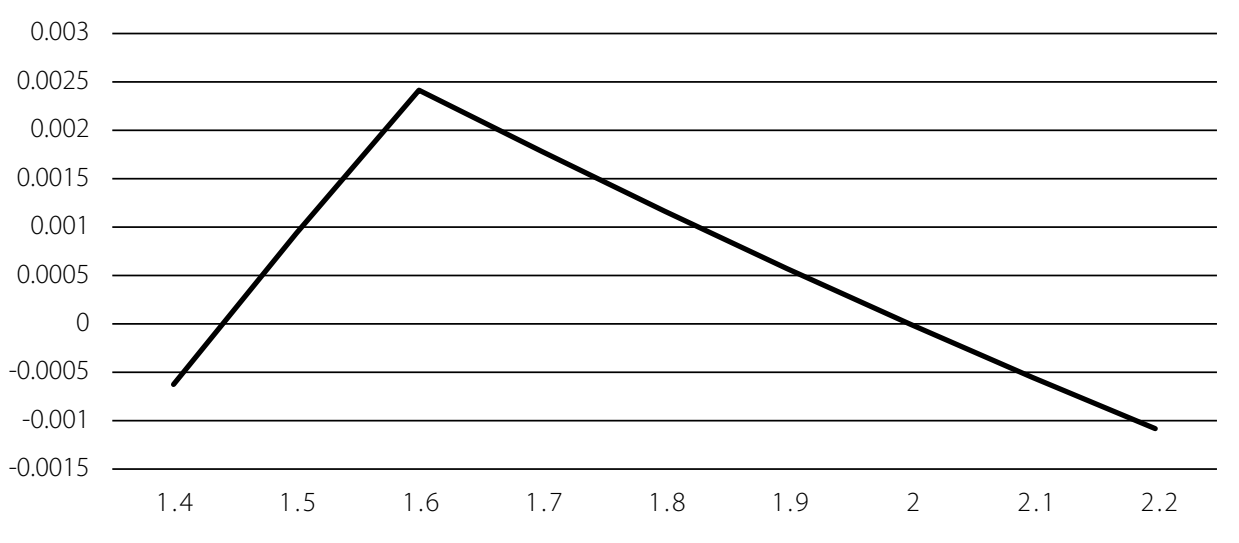

Social Welfare equilibrium path values under different values of $\boldsymbol{t}$

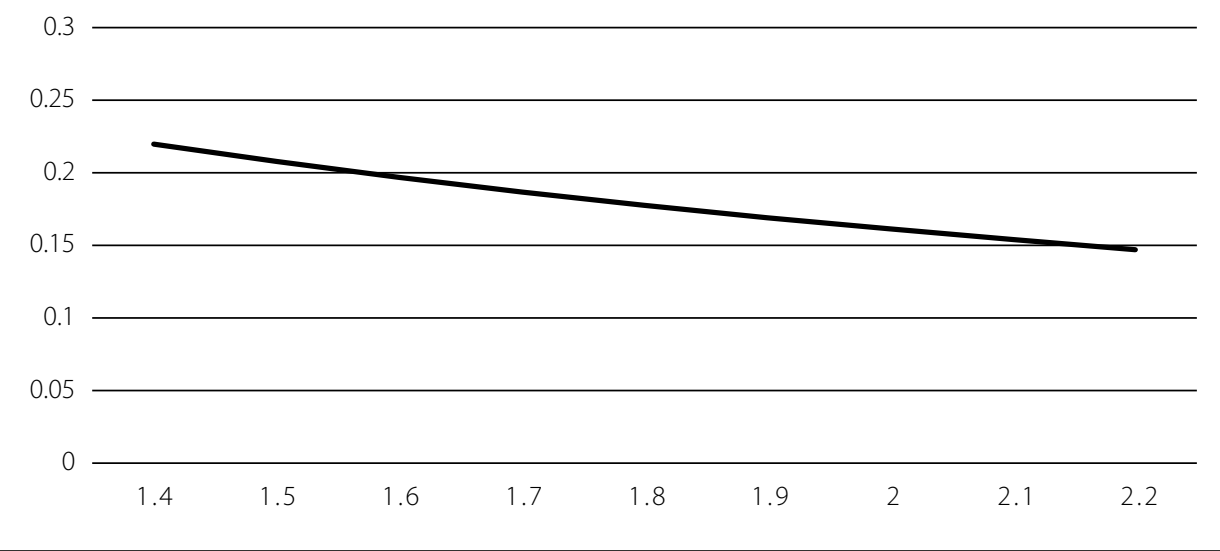




\section{4}

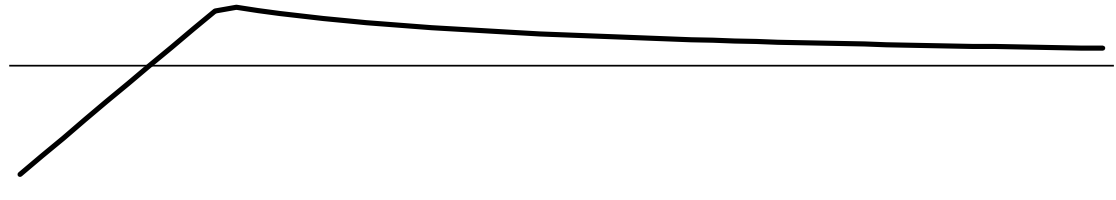

99.3

99.2

$\begin{array}{lllllllllll}0 & 0.5 & 1 & 1.5 & 2 & 2.5 & 3 & 3.5 & 4 & 4.5 & 5\end{array}$

Market Makers' buying equilibrium price path values under different

values of $t$ (whereby $v=100.5, B(2)=1, k=0.2, r=99, \gamma=1, L=8$,

$N=2$ and $f=0.0255)$.

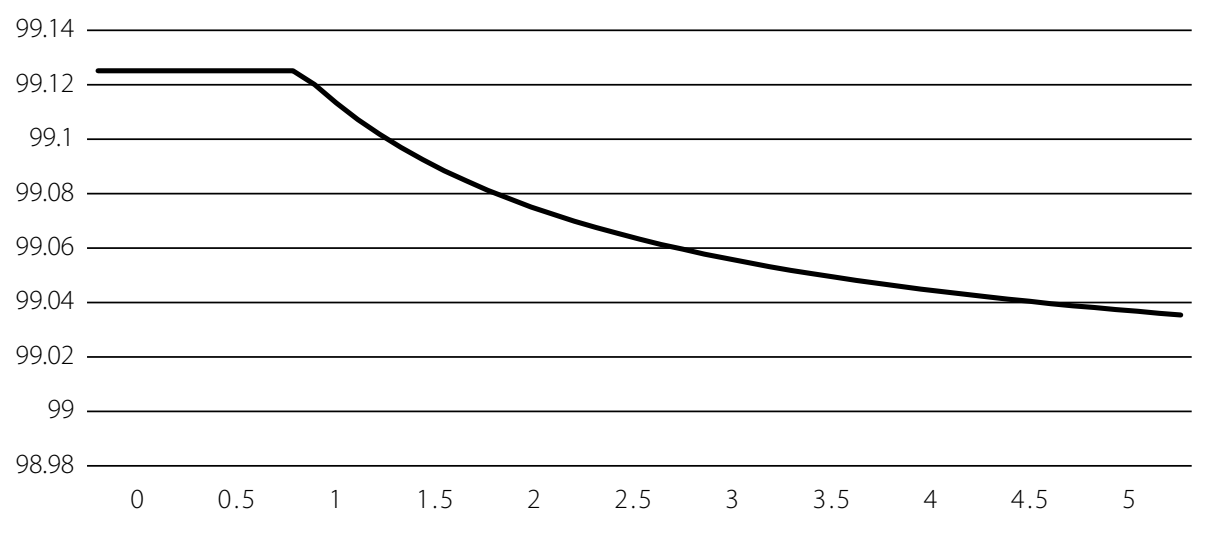

Market Makers' equilibrium mark-up, $p-q-k$, path under different values of $t$ (whereby $v=100.5, \beta(2)=1, k=0.2, r=99, \gamma=1, L=8$, $N=2$ and $f=0.0255)$.

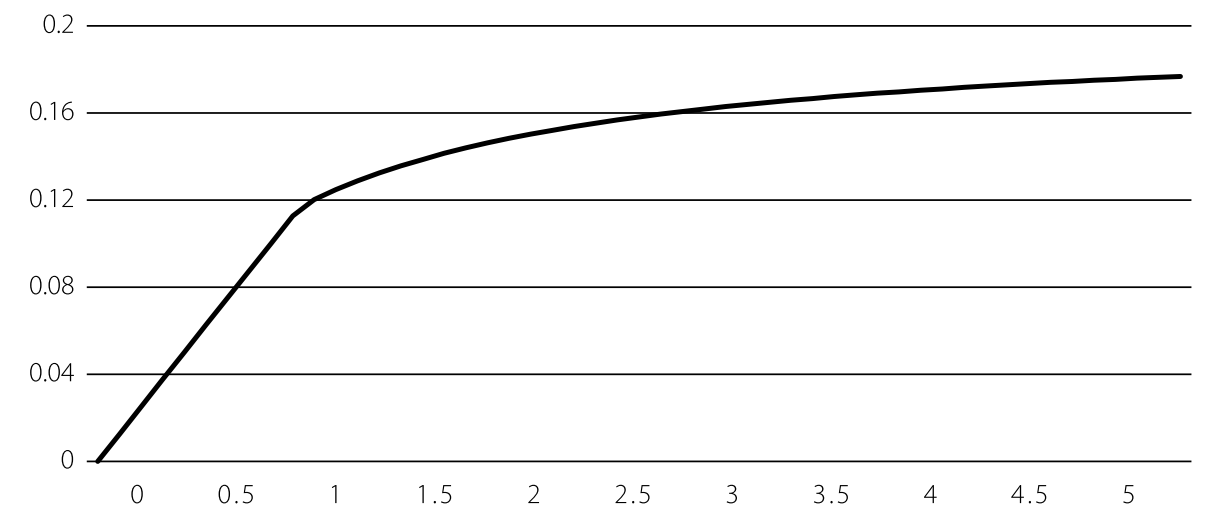


Market makers' equilibrium profit path under different values of $\gamma$ (whereby $v=100.5, B(4)=1, k=0.2, r=99, t=2, L=8, N=2$ and $f=0.0255$ ).

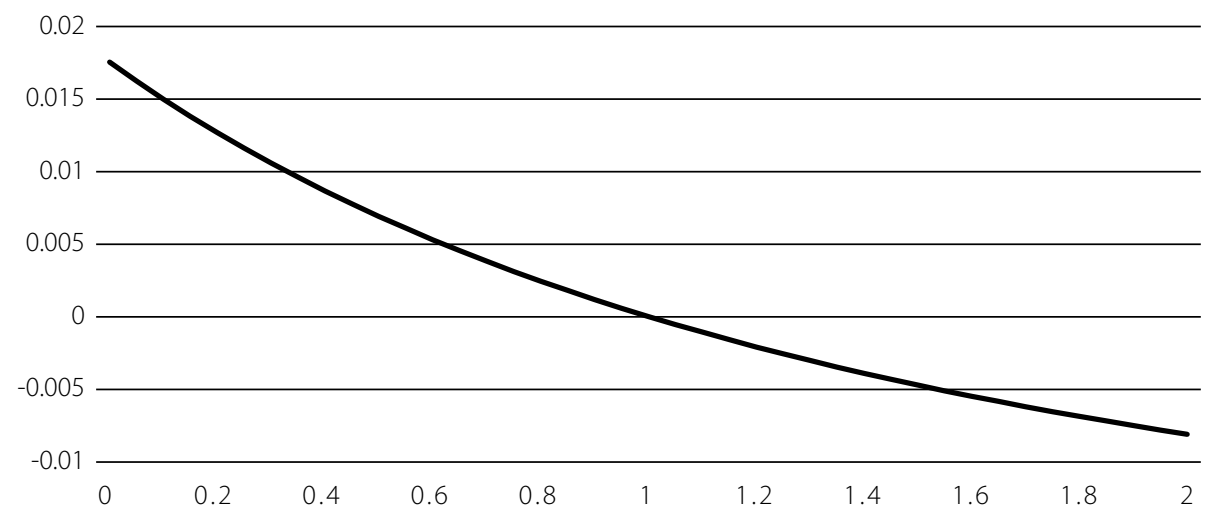
(whereby $v=100.5, B(2)=1, k=0.2, r=99, t=2, L=8, N=2$ and $f=0.0255$ ).

0.3

0.25

0.2

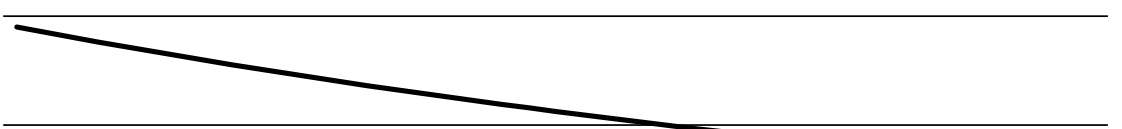

0.15

0.1

\begin{tabular}{lllllllllll}
\hline 0 & 0.2 & 0.4 & 0.6 & 0.8 & 1 & 1.2 & 1.4 & 1.6 & 1.8 & 2
\end{tabular}

Market Makers' selling equilibrium price path values under different values of $\gamma$ (whereby $v=100.5, B(2)=1, k=0.2, r=99, t=2, L=8$, $N=2$ and $f=0.0255$ ).

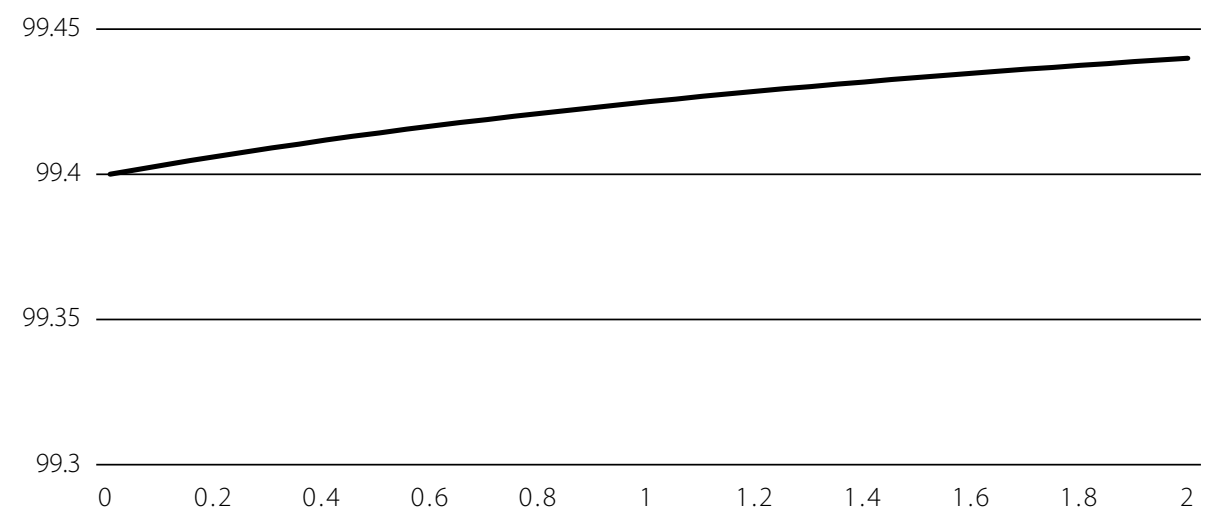


values of $\gamma$ (whereby $v=100.5, B(2)=1, k=0.2, r=99, t=2, L=8$,

$N=2$ and $f=0.0255)$.

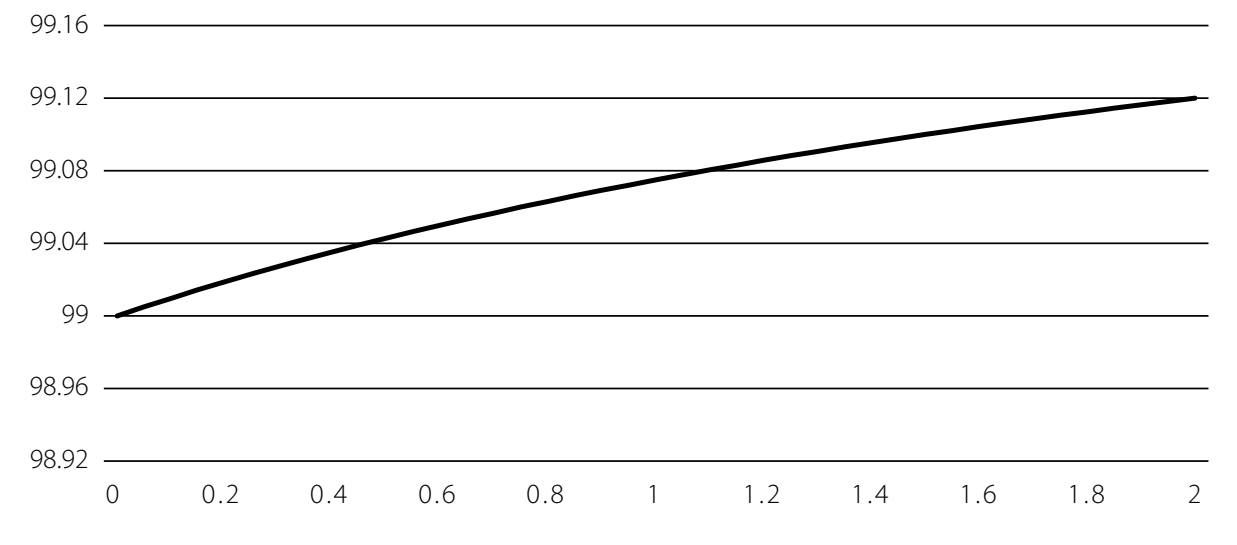

Market Makers' equilibrium mark-up, $p-q-k$, path values under different values of $\gamma$ (whereby $v=100.5, \beta(2)=1, k=0.2, r=99, t=2$, $L=8, N=2$ and $f=0.0255$ ).

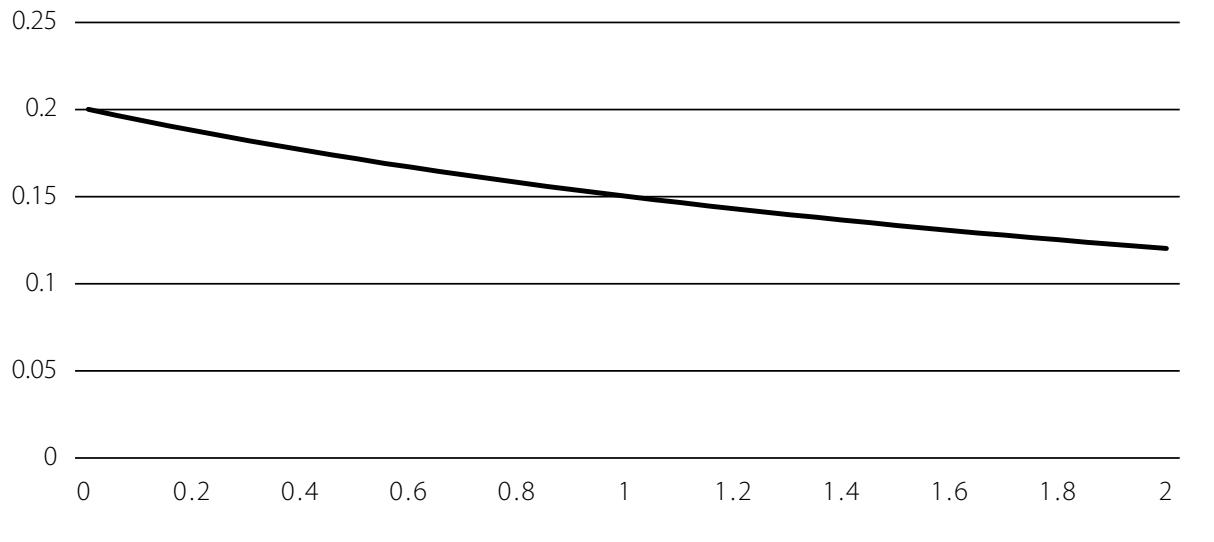






